\title{
DA NECESSÁRIA CONSTITUCIONALIZAÇÃO DO DIREITO INTERNACIONAL - UMA PERSPECTIVA DESDE A TEORIA DE ALF ROSS
}

\author{
THE NECESSITY TO CONSTITUTIONALIZE INTERNATIONAL LAW -A \\ PERSPECTIVE FROM THE THEORY OF ALF ROSS
}

\author{
Vidal Serrano Nunes Junior \\ Procurador de Justiça, Livre-Docente em Direito Constitucional, Diretor Adjunto da \\ Faculdade de Direito da Pontifícia Universidade Católica de São Paulo - PUC-SP, \\ Professor do programa de pós-graduação -stricto sensu- da PUC-SP - e-mail: \\ serranonunesjr@gmail.com \\ Luiz Sales do Nascimento \\ Promotor de Justiça, Mestre e Doutor em Direito Constitucional pela PUC-SP, Professor \\ do programa de pós-graduação -stricto sensu- em Direito da Universidade Católica de \\ Santos - UNISANTOS- email:profsalesorientador@bol.com.br
}

Recebido em: 06/05/2017

Aprovado em: 16/08/2017

Doi: $10.5585 /$ rdb.v17i7.687

RESUMO: O presente trabalho analisa a evolução da filosofia do direito, especialmente no que tange à epistemologia do positivismo jurídico, visando o estudo da validade e eficácia do Direito Internacional. Partindo das teorias de Hans Kelsen, Herbert Hart, e Robert Alexy, procura-se demonstrar que é Alf Ross, um dos expoentes da denominada Escola Realista do Direito, quem elabora a teoria mais consentânea com o fenômeno jurídico decorrente das relações entre o Direito Internacional e o Direito Interno de cada Estado. Objetiva-se provar que, no atual estágio do Direito Internacional, sua validade e eficácia dependem da sua constitucionalização.

Palavras-chave: Positivismo Jurídico; Direito Internacional; Direito Constitucional; Direito Interno.

\begin{abstract}
The present work analyses the evolution of law philosophy, especially concerning to juridical epistemology positivism, aiming at the study of the validity and effectiveness of International Law. Starting with the theory of Hans Kelsen, Herbert Hart and Robert Alexy, the attempt is to show that it is Alf Ross, one of the exponents of the Legal Realism, whom elaborates the theory most consentaneous to the juridical phenomenon deriving from the interrelationship between international law and each State's internal law. The objective is to prove that, at the present stage of international law, its validity and effectiveness depend on its constitutionalization.
\end{abstract}

Key Words: Juridical Positivism; International Law; Constitutional Law; Domestic Law. 
SUMÁRIO: Introdução. 1. A filosofia do Direito Natural. 2. Alexy e uma síntese do positivismo jurídico e do jusnaturalismo. 3. O positivismo jurídico de Kelsen. 4. O positivismo jurídico de Hart. 5. O monismo e o dualismo jurídicos. 6. O realismo de Alf Ross. Conclusão. Referências.

\section{INTRODUÇÃO}

$\mathrm{Na}$ atual fase de desenvolvimento do direito internacional, especialmente no que tange à sua eficácia, parece-nos importante uma teoria científica que efetivamente explique como as normas jurídicas deste ramo do direito alcançam os povos dos Estados.

Se as normas jurídicas das organizações internacionais gozam de baixa densidade, sendo, por isso mesmo, chamadas de soft law, fato é que, mesmo os tratados encontram dificuldades para serem aplicados pelos tribunais na solução de conflitos de interesses internos nos Estados.

A filosofia do direito, não aquela parte que se ocupa da axiologia, nem da hermenêutica, mas sim a que cuida da epistemologia, deve refletir a realidade do direito em ação, isto é, da eficácia das normas jurídicas de direito internacional na solução de casos concretos. Assim, a filosofia do direito natural mereceu ser historiada com o objetivo de demonstrar como está ultrapassada para explicar essa relação dialética entre o direito internacional e o direito interno estatal. E se ela foi suplantada pelo positivismo jurídico, buscou-se demonstrar como as suas principais e consagradas teorias, como as de Kelsen e Hart, também não são servientes para explicar o direito internacional em ação nos dias de hoje.

Então, apresenta-se a teoria de Alf Ross, expoente da Escola Realista do Direito, que confrontada com as duas outras acima citadas, mostra-se a única capaz de refletir a dinâmica de constitucionalização do direito internacional, como única senda para a efetivação daquele direito.

\section{A FILOSOFIA DO DIREITO NATURAL}

A concepção de direito natural é, em síntese, e de forma reducionista, a de um direito que sempre existiu, existe, e sempre existirá, enquanto houver sociedade humana organizada. É, portanto, um direito imutável, e de certa forma eterno, se considerarmos a existência humana como eterna.

As coisas no mundo (fenômenos físicos e sociais) se modificam, apenas o direito é imutável (Strauss, 2014, p.117). Trata-se da expressão maior do antigo adágio romano $u b i$ societas, ibi jus (havendo sociedade, há direito). E como parece óbvio, a construção desse direito decorreu da necessidade na busca de proteção em algo absoluto contra as incertezas que marcaram o alvorecer das sociedades primitivas.

Colimava a paz e a segurança contra as dúvidas da existência incerta, e as ansiedades geradas por ela, aplacando os poderes que dominavam o homem (Ross, 2007, p. 268). É da sabença geral a evolução e o refinamento que a concepção do direito natural sofreu durante a Idade Média, com Santo Agostinho e São Tomás de Aquino, entre outros filósofos que contribuíram, uns mais, outros menos, para a escalada de solidificação dessa concepção de direito.

E se nasceu e evoluiu assim, fundado na magia e na religião, com o advento do iluminismo ganhou contornos racionalistas. Deixando de lado o caráter sagrado, ele se transformou agora imerso na especulação filosófica, em pura metafísica.

No século passado, nada obstante o positivismo jurídico ter suplantado a concepção jusnaturalista do direito, esse último ainda tentou uma sobrevida (Mayer, 1937, pp. 57/59), com Georgio Del Vechio e outros (Del Vecchio, 1953, p. 515). 


\section{ALEXY E UMA SÍNTESE DO POSITIVISMO JURÍDICO E DO JUSNATURALISMO}

Entretanto, em pleno século XXI, muitos filósofos do direito, como o alemão Robert Alexy, por exemplo, parecem ter vestido a velha antítese entre o jusnaturalismo e positivismo jurídico com um disfarce pós-moderno, objetivando o ressurgimento do Direito Natural de forma mascarada.

Alexy, em seu livro "Conceito e Validade do Direito", parte da análise de dois casos concretos julgada pela Corte Constitucional Alemã que foge da perspectiva positivista do legalismo estrito, e que não encontra, nessa concepção, uma solução justa (Alexy, 2011, pp.6/12). São o que ele chama de casos extremos.

São os casos de um judeu alemão que fugiu de seu país durante a ascensão do nazismo, perdendo sua nacionalidade, nos termos da lei do Reich, retornando à Alemanha após o fim do conflito bélico mundial, ocasião quando então pleiteou o reconhecimento de sua nacionalidade, embora não houvesse uma lei que o permitisse; e o da esposa do último Xá do Irã, entrevistada por revista alemã, que não apenas a distorceu, mas também veiculou fatos mendazes a seu respeito, provocando-lhe danos imateriais.

No primeiro caso, instada a julgar o caso, a Corte Constitucional entendeu que o direito e a justiça não estão à disposição do legislador, que pode estabelecer leis injustas. Aplicadas na solução de um conflito de interesses concreto, os magistrados estariam estabelecendo o reino do injusto, e não do direito, motivo pelo qual a referida lei deveria ser, como de fato foi, declarada nula porque inválida. Com efeito, adverte Alexy, se hoje pensarmos em regimes políticos que afrontem direitos humanos, quando esse governo acabar, seus integrantes só serão punidos por terem obedecido a leis injustas se houver uma lei retroativa, ou se essas normas forem consideradas nulas (Alexy, 2011, p ).

No segundo caso, a ação de indenização foi julgada procedente, mesmo com o Código Civil alemão restringindo o cabimento de indenização por danos imateriais apenas nas situações arroladas naquele diploma legal, o que não era o caso então sub judice. A Corte, no entanto, fugindo à visão positivista, que vislumbraria tal decisão como extrajurídica, entendeu que o direito não é composto pela totalidade das leis escritas, podendo existir "excessos" em certas circunstâncias, corrigíveis pela jurisprudência, apoiada essa na fonte do direito constitucional, que se consubstancia como um conjunto de sentido.

De fato, deve o juiz realizar a ponderação entre os princípios, que funcionam como mandamentos de otimização para chegar a uma decisão ao mesmo tempo racional e justa. E tudo porque o direito deve ter, para Alexy, um caráter corretivo da extrema injustiça. Por isso a decisão judicial pertence ao direito e à moral, que, juridicizada, dá à decisão seu caráter jurídico.

Assim, uma norma jurídica será válida se, como para Hans Kelsen, for feita por quem tem competência para fazê-la, de acordo com o devido processo legislativo, com um mínimo de eficácia, e que não seja extremamente injusta. Aliás, é esse aproveitamento da teoria do filósofo austríaco, que reconhece o direito em uma legalidade conforme o ordenamento dotado de autoridade e eficácia, mais a questão do direito como correção, que levam alguns doutrinadores a concluir que Alexy não é um jusnaturalista, e sim o filósofo que conseguiu eliminar a antítese direito natural/direito positivo.

Entretanto assim não nos parece. Dentro da perspectiva da filosofia do direito, dividida em axiologia, hermenêutica e epistemologia, a teoria de Alexy parece se encaixar mais no ramo da axiologia, vale dizer como o direito deve ser. Alexy não diz como o direito é, objeto da epistemologia. É claro que podemos intuir que, aproveitando-se da teoria de Kelsen, para ele o direito é um sistema de normas postas com pretensão de correção.

Ocorre que esse elemento subjetivo da pretensão à correção não é do direito, e sim de quem o opera. E não há nenhuma evidência que todos os homens que manejam o direito tenham a 
pretensão de correção. É preciso saber o que é o direito de forma científica. E o positivismo jurídico procura essa definição. Mas o que é o positivismo?

\section{O POSITIVISMO JURÍDICO DE KELSEN}

O positivismo jurídico é como um ramo do positivismo sociológico, nascido com Augusto Comte, que passou a cuidar da ciência rechaçando a descoberta de princípios a partir de deduções a serem utilizadas a priori. As ciências devem partir do positivo, isto é, dos dados. Dados são fatos. O positivo (dados, fatos) não tolera a metafísica, o transcendente, o suprassensível.

Por isso Émile Durkheim concluiu que o método dedutivo na busca de princípios a serem utilizados como um a priori para a descoberta do jurídico, utilizado pelo Direito Natural, não era histórico e, portanto, desconforme com a realidade (Montoro, 1980, p. 100).

O Direito Natural nada mais é do que o que a consciência coletiva estabeleceu como o direito em um determinado tempo e espaço. O direito não é, portanto, universal e atemporal. Cada comunidade político-jurídica tem seu próprio ordenamento.

Dos diversos filósofos positivistas do direito contemporâneo, avulta Hans Kelsen, que como todos sabem procurou livrar o direito da influência de outras ciências ao estabelecer que o objeto da ciência do direito é a norma jurídica, seja no estudo estático ou dinâmico. E como é da sabença geral, em seu livro "Teoria Pura do Direito", definiu-o como um ordenamento de coerção normativo.

Trata-se de uma ordem normativa que procura produzir uma conduta humana determinada pelo fato de ela prescrever uma conduta e, no caso de uma conduta oposta, denominada antijurídica, dever-se aplicar um ato de coerção, chamado de sanção. Sua existência se expressa na validade. E a positividade se revela na validade da norma jurídica condicionada pelos fatos. E é essa validade que revela a existência da norma, que nada mais é, que o sentido atribuído ao fato.

É conhecida a ruptura que Kelsen estabelece entre o mundo do ser, no qual se encontram os fatos, como condição de validade das normas jurídicas, e o mundo do dever ser, no qual se situa a própria validade, capaz de produzir a vinculação de todos à norma. A norma jurídica válida é aquela que foi feita por quem tem competência para fazê-la segundo norma de um escalão superior, de acordo com o devido processo legislativo, consoante norma hierarquicamente superior, e com um mínimo de eficácia.

Como se vê, a norma jurídica, no plano do dever ser, extrai sua validade de normas jurídicas de um extrato mais alto, até chegar à norma hipotética fundamental. Essa última é um artifício lógico-jurídico para o direito se apresentar com um sistema fechado, inerme à influência de outras ciências ou mesmo da moral.

Ocorre que essa norma tem caráter transcendental e, portanto, metafísico. Logo, está afastada da realidade.

\section{O POSITIVISMO JURÍDICO DE HART}

Outro grande positivista contemporâneo é o inglês Herbert Hart. Em seu livro "O Conceito de Direito" explica não haver um conceito unânime do que vem a ser direito, e que talvez nem fosse necessário conceituá-lo, uma vez que o homem comum reconhece a existência de regras de conduta acompanhadas de sanção para o caso de descumprimento, bem como de um Poder Legislativo para elaboração das referidas normas e de um Poder Judiciário para interpretar e aplicar a norma jurídica genérica e abstrata na solução de um caso concreto e particular. Assim, como para outros filósofos do Direito, a característica do direito estaria na coerção. 
Ele então aponta dificuldades para uma conceituação de direito de forma científica, isto é, universal e atemporal, uma vez que o direito primitivo, e o Direito Internacional, não encontram assento em um sistema concentrado de sanções.

O direito em sociedades primitivas possuía defeitos, quais sejam: a incerteza, o caráter estático de suas normas e a ineficácia (Hart, 2011, pp. 101/109). A superação desses defeitos encontra-se na existência de normas primárias e secundárias no direito das sociedades modernas, configuradas sob o padrão da alta complexidade. As regras primárias, que também existiram nas sociedades primitivas, e existem no Direito Internacional, são aquelas que impõem obrigações de um fazer ou de um não fazer. Já as regras secundárias são aquelas que reconhecem as normas primárias como jurídicas, por exemplo, porque constam de um texto legal, e são chamadas de normas de reconhecimento. São também as denominadas regras de alteração, isto é, aquelas que possibilitam a modificação ou supressão de uma norma jurídica que já não interesse mais à sociedade. E por fim, as normas de julgamento, que cuidam da organização de um corpo de magistrados, e da sua competência de julgamento.

O fundamento de validade do direito é a aceitação, pela comunidade, das regras secundárias de reconhecimento (Hart, 2011, p.117). Esses dois expoentes da filosofia jurídica positivista do século XX, Kelsen e Hart, vislumbraram a relação entre o direito estatal e o direito internacional sob perspectivas diferentes.

\section{O MONISMO E O DUALISMO JURÍDICOS}

Kelsen era monista. Hart, dualista. O monismo de Kelsen se apoia também da sanção como característica central do direito.

Com base em Hugo Grócio, que cuidou das guerras e represálias como sanções do direito internacional, o filósofo de Viena adverte que represália e guerra são as sanções, e a ofensa que as desencadeia são o ilícito (Kelsen, 1979, p. 428). A represália que não configurar uma reação a um ilícito de direito internacional, é ela própria um ilícito condenado pelo mesmo direito. E o direito internacional é composto por normas jurídicas que impõem direitos e obrigações a todos os Estados. E entre essas normas ganha relevância o pacto sunt servanda, que autoriza, por meio de tratados, que a comunidade jurídica internacional regule as condutas recíprocas entre os Estados e seus súditos com outros Estados e seus próprios súditos. E esses tratados vão criar órgãos e tribunais internacionais, capazes de elaborar outras normas de direito internacional.

Na visão de Kelsen, essas normas vão se apoiar em outras normas, de um grau superior, isto é, nos tratados que as instituiu, que fazem parte do Direito Internacional, que, por sua vez, se apoiam em normas de um grau ainda superior, qual seja as que compõem o Direito Internacional Geral Consuetudinário, e este, em uma norma fundamental pressuposta do Direito Internacional. Essa última institui como fato gerador do direito o costume constituído pela conduta recíproca entre os Estados.

Essas normas jurídicas internacionais são tão normas jurídicas como aquelas formuladas pelos Estados, de sorte que a Ciência do Direito só pode considerá-las em relação umas às outras. É que para ele, assim como as ciências da natureza, a Ciência do Direito deve descrever seu objeto, qual seja a norma jurídica, na sua unidade. Não se pode descrever como válida uma norma que prescreve Se é A, então deve ser B, se outra diz Se é A, então não deve ser B (Kelsen, 1979, p. 438).

Essa visão monista de Kelsen, que sistematiza todo o direito, estatal e internacional, como um só, resolveria a antinomia entre as normas de direito internacional e as do direito estatal.

De fato, não há contradição entre as duas ordens jurídicas, porquanto mesmo que haja leis de Direito Internacional, elas continuarão a vigorar, porque não há nenhum processo jurídico 
para anulá-las. A mesma ordem jurídica estatal pode prever a responsabilização do órgão que criou a lei inconstitucional, mas como ele tem competência para fazê-las, e seguiu o devido processo legislativo, a referida lei continuará válida. E assim, o direito internacional e o direito nacional podem conviver em uma única ordem jurídica mundial.

O direito não se define pelo seu conteúdo, mas pela forma como as normas jurídicas são produzidas. Então, o direito criado de acordo com os costumes, pactos, e decisões de órgãos ou tribunais internacionais, se reconhecidos, tácita ou explicitamente pela ordem jurídica de um Estado, com fundamento último de validade na norma fundamental pressuposta desse mesmo Estado, nós teremos uma ordem jurídica única ${ }^{1}$.

Já Herbert Hart, dizer que o direito internacional não é vinculativo porque não tem um sistema de sanções organizadas, não tem nenhum sentido. Como já visto, para ele, o direito não é um sistema coercitivo de ordens. Em verdade, Hart reconhece a dificuldade de compreender o direito internacional como direito porque inexiste um Poder Legislativo internacional, nem tribunais com jurisdição obrigatória, nem um sistema organizado de sanções. Falta-lhe, para qualificá-lo como direito, regras de reconhecimento e de julgamento, e inclusive uma regra última de reconhecimento unificadora, que especifique as fontes do direito e identifique suas regras.

Ele demonstra que se não existissem as sanções, os crimes ocorreriam a todo o momento, mas no âmbito internacional, embora não hajam sanções, ocorrem longos períodos de paz. E, por fim, o direito internacional encontra dificuldade na existência da soberania estatal, que em última análise significa que o Estado é independente.

Quando as regras de reconhecimento são aditadas às normas primárias de obrigação, ela permite a identificação das normas do sistema, e ainda se pode perguntar: qual norma do sistema torna essa regra vinculativa, vale dizer, qual a razão da sua validade?

Em verdade, o direito internacional vem evoluindo muito desde a última grande guerra mundial, mas assemelha-se ao direito interno de um Estado apenas no que tange ao seu conteúdo, não à forma. Daí que o dualismo de Hart permita aos juristas transitarem de um âmbito para o outro, manejando analogias de conteúdo que consistem em uma série de princípios, conceitos e métodos jurídicos.

Essas concepções, monista e dualista, vão sendo ultrapassadas pela ideia do diálogo constante das fontes do direito internacional e do direito estatal. (Mazzuoli, 2010, pp. 130/132).

E essa relação dialógica prática pode ser bem acomodada à teoria de Alf Ross.

\section{O REALISMO DE ALF ROSS}

O filósofo dinamarquês Alf Ross é materialista.

O materialismo é uma concepção de mundo que parte do dogma segundo o qual a matéria é eterna, e que ela prevalece e determina o espírito, isto é, o mundo ideal. O pensamento de Alf Ross, exposto em seu livro "Direito e Justiça", parece mais consentâneo com a realidade do direito internacional em ação.

Conquanto se apoie em Kelsen no que tange à centralidade da coerção na composição do fenômeno jurídico, e perceba os magistrados como destinatários da ordem jurídica, ele logra demonstrar como o jurista austríaco também incide no erro metafísico de abordar a validade da norma jurídica (objeto de estudo da Ciência do Direito) como algo que se encontra em um mundo à parte da realidade, isto é, no mundo do dever ser.

Pretendendo agir com neutralidade axiológica, Kelsen se aparta da realidade. Afinal, o Direito é fenômeno social, um dado sensível e empírico, e como tal deve ser estudado. Por isso,

\footnotetext{
${ }^{1}$ Há uma outra concepção monista, não preferida, mais aceita por Hans Kelsen, que não interessa ao presente
} trabalho.

Revista de Direito Brasileira | São Paulo, SP | v. 17 | n. 7 | p. 408 - 417 | Mai./Ago. 2017 
Ross não conceitua o Direito, uma vez que cada ordenamento jurídico tem sua própria peculiaridade, com existência real conferida por coerência e significado.

Ao fazer uma analogia com o jogo de xadrez, Ross demonstra que qualquer pessoa saberá que se trata de um jogo quando este estiver sendo jogado. A predição das jogadas, no entanto, exige que o observador externo conheça as regras. A referida predição será mais exata, se este terceiro, além de conhecer as regras, conhecer também a teoria, a compreensão, e os objetivos de cada jogador. As jogadas, que são movimentos físicos, e motivam a jogada subsecutiva do adversário, não são provocadas por relações de causa e efeito, e sim pelo conhecimento, maior ou menor, de cada jogador, acerca das regras e teorias do jogo de xadrez. A conexão, portanto, não é de causa e efeito, porém de significado.

Ao utilizar o exemplo analógico do jogo, com a compreensão sobre regras e teorias, Ross demonstra como o Direito é um esquema de interpretação da realidade social. As ações humanas ganham significado à medida que se relacionam com as regras comuns do jogo social.

As regras primárias, que são as regras de conduta, por exemplo, são encaradas como obrigatórias pelos jogadores, que estão motivados espontaneamente, e sabem que a sua inobservância provocará um protesto no seu oponente. A existência dessas regras (normas jurídicas), isto é, a sua vigência, depende de um jogo concreto. Então, é no jogo efetivamente jogado que o observador externo verifica quais regras os jogadores se sentem obrigados a respeitar. E isto se dá, porque as normas jurídicas, assim como as regras de xadrez, não têm existência real.

A norma jurídica contém um ideal abstrato, que enseja, como um esquema de interpretação, a compreensão dos fenômenos jurídicos, isto é, do direito em ação. Essa compreensão leva a que se vislumbre o Direito em ação como um todo de significado e motivação.

O Direito em ação, e a norma jurídica em si, são as duas faces da mesma moeda. Com efeito, nenhuma ação físico-biológica tem significado jurídico, só adquirindo tal caráter ao ser interpretada conforme o esquema em que se constitui a norma jurídica. Da mesma forma, o conteúdo abstrato da norma jurídica não tem validade, a não ser que possa ser efetivamente aplicada como um esquema de interpretação.

Ensina Ross que a vida em sociedade não é um caos de ações individuais isoladas. As ações adquirem significado quando se relacionam com as regras comuns do jogo social. E é a consciência dessas regras que possibilita o entendimento e a predição do curso dos eventos.

Então, se a regra do xadrez é vigente se efetivada na realidade do jogo jogado, conforme observação externa, e como são sentidas por cada jogador como socialmente obrigatórias, também é vigente a norma jurídica efetivada na realidade social, conforme a observação externa, e como são sentidas pelos indivíduos como socialmente obrigatórias, isto é, vinculantes, vale dizer válidas.

A norma jurídica é um esquema de interpretação da realidade (Ross, 2007, p. 41). O Direito vigente é o conjunto de normas de dever ser que serve de esquema interpretativo para os fenômenos do Direito em ação, o que significa que essas normas são efetivamente acatadas, e que o são porque são experimentadas e sentidas como socialmente obrigatórias.

Por isso, o Direito só pode ser estudado em duas frentes interligadas, quais sejam as da Ciência do Direito e da Sociologia do Direito (Ross, 2007, p. 45). A Ciência do Direito se ocupa das normas jurídicas, e a Sociologia do Direito, do direito em ação, vale dizer do fenômeno jurídico.

Ross preconiza o estudo entrelaçado entre as duas ciências, sem o que a teoria não refletirá a realidade que pretende descrever. É que o jurista só estudará o direito vigente se estudar as normas idealmente consideradas em relação com a vida real, porque aí reside o direito válido. Válido porque eficaz enquanto constitutivo de um fato social. Note-se que o juiz também não é motivado apenas pelas normas, mas também pelos fins sociais a que se destinam. $\mathrm{O}$ 
magistrado precisa ter o conhecimento teórico das conexões sociais, devendo considerar a realidade da vida.

As normas jurídicas, como o jogo de xadrez, servem como um esquema interpretativo correspondente a um conjunto de atos sociais, isto é, o direito em ação. Somente assim é possível compreender essas ações como um todo coerente de motivação e significado, e predizer cada uma das ações dos vários atores sociais. E as normas de conduta são dirigidas aos magistrados, que as usam como esquema de interpretação para decidir.

O direito é dirigido aos membros da comunidade, isto é, aos particulares, apenas de uma forma figurada, com função ideológica. $\mathrm{O}$ indivíduo em contato com a norma tem ciência de como os tribunais poderão reagir, e adaptar sua conduta às reiteradas decisões em um mesmo sentido. Há outro tipo de normas jurídicas além das de conduta. São as normas de competência. Ambas estão unidas, formando uma unidade, que é o ordenamento jurídico.

Essas normas de competência também são dirigidas aos magistrados. E se o indivíduo não aceitar a sentença judicial, estará sujeito ao uso legítimo da força física contra ele. Este manejo da força é legítimo, porque o juiz é a pessoa qualificada pela norma de competência para determinar o uso da violência legal. Onde há Estado, aí estará o monopólio do uso da força.

Portanto, o ordenamento jurídico nacional é o conjunto de regras para o estabelecimento e funcionamento do aparato de forças do Estado. Ross demonstra que a unidade do sistema reside no fato de que as normas de conduta, e as normas de competência dizem respeito ao uso da força pela autoridade pública. E o juiz as aplica porque as tem como socialmente obrigatórias.

Ao aplicar a norma jurídica genérica e abstrata para dirimir um conflito de interesses concreto e particular, o magistrado a maneja como um esquema de intepretação, que só então ganha sentido com a realidade subsumível.

Logo, a vigência das normas jurídicas depende do uso que delas fazem os tribunais, independentemente de as pessoas do povo as observarem (Ross, 2007, p. 61). Norma jurídica vigente, portanto, é aquela que o observador externo verifica que é aplicada com regularidade pelos tribunais. Essas normas são aplicadas com regularidade pelo Poder Judicial, porquanto havidas como socialmente obrigatórias pelos magistrados (Ross, 2007, p. 79). Podemos dizer que para Alf Ross norma jurídica vigente é a norma jurídica válida.

A validade não está vinculada às normas jurídicas de um escalão superior até abicar na norma hipotética fundamental. Esse artifício lógico jurídico inventado por Kelsen consubstanciase em pura metafísica, da qual a ciência do direito deve ser afastar para descrever com rigor o seu objeto, isto é, o sistema de normas postas, e o direito em ação. Ao tratar da aplicação das normas jurídicas pelos juízes, Ross adverte que essa questão exige reflexão acerca das fontes do direito. $\mathrm{E}$ as fontes variam conforme os sistemas adotados.

Na Europa continental, e nos países da América do Sul, por exemplo, a principal fonte é a lei, fundamentalmente porque a doutrina sustenta a sua força obrigatória. Entretanto, não raras vezes, os magistrados desconsideram as regras postas pelo parlamento, por considerarem que está em desacordo com a realidade objetiva que se transformou.

Esse exemplo demonstra, claramente, como a filosofia de Alf Ross descreve a realidade com precisão. Um positivista jamais admitiria, porque não se vale da Sociologia do Direito para estudar o fenômeno jurídico, que uma decisão contra legem fosse tomada, sem perder com isso sua natureza jurídica.

Sua teoria é, pois, mais rica e precisa que a do positivismo legalista estrito, que tem preponderado no estudo da Ciência do Direito, e mais fértil e certeira que as teorias denominadas pós-modernas, como a de Robert Alexy. 
Há outras fontes também, como os costumes e os precedentes ${ }^{2}$. Entretanto, Alf Ross chama a atenção para a tradição cultural como fonte do direito, especialmente nos casos de lacunas (Ross, 2007, p. 124).

Tradição cultural é o conjunto de mitos, poesia, religião, idiossincrasias de uma coletividade, que implica em uma filosofia de vida, em uma combinação de valores e uma mundividência. A tradição cultural ganha novas dimensões e contornos com a substituição de um modo de produção por outro ${ }^{3}$, e o surgimento de novas tecnologias ${ }^{4}$.

Assim como a sociedade, que está em constante movimento, nos termos da dialética já desde Heráclito, a tradição cultural também se modifica. E a verdade é que as normas jurídicas são incompreensíveis se isoladas do meio cultural em que plantadas. A aplicação mecânica da norma jurídica, sem considerar o meio cultural no qual se encontra o magistrado, é um non sense.

Para que a decisão judicial alcance o seu propósito de encerrar um litígio de forma ótima, ela deve ter um significado, que só pode estar ancorado na tradição cultural.

Aqui Alf Ross rejeita a postura positivista, que não leva em consideração a atmosfera cultural na aplicação do direito, e a postura dos adeptos do jusnaturalismo, que interpretam o direito de forma metafísica, com um direito natural baseado em um discernimento racional a priori.

O filósofo sob comento divide o direito em público e privado. Público é aquele concernente à posição jurídica das autoridades públicas (pessoas com o encargo acompanhado de sanções e medidas de controle para o exercício incorreto da competência), isto é, a sua constituição, suas competências, atribuições, prerrogativas, e deveres. Em síntese, são as normas de competência (Ross, 2007, p. 239). O direito privado comporta todas as demais normas jurídicas, vale dizer as normas de comportamento ${ }^{5}$.

Em um Estado Democrático de Direito, o direito público se divide em três categorias que se referem aos atos legislativos, administrativos, e judiciários. Podemos concluir, portanto, que até mesmo o direito internacional não é, no atual estágio do seu desenvolvimento, direito público.

É que ao direito internacional falta o elemento de unificação do sistema normativo, que como vimos é o uso da força pela autoridade pública, a que se ligam tanto as normas de conduta, quanto as normas de competência.

\section{CONCLUSÃO}

Dentro dessa concepção do realismo jurídico de Alf Ross, o direito internacional, ao menos no atual estágio, dada a baixa densidade de suas normas, especialmente aquelas editadas por organizações internacionais, denominadas por isso mesmo de soft law, estão no meio do caminho, talvez mais próximas de um direito privado convencional, trocando-se a ideia de indivíduo pela de Estado, que exerce sua competência privada livremente, conforme seus interesses, obrigando apenas aqueles outros Estados que consentem com as cláusulas a que se obrigaram por tratado.

\footnotetext{
${ }^{2}$ Os precedentes vão ganhando cada vez mais proeminência no mundo globalizado, porque a predição de como vão se comportar garantem segurança jurídica. Uma multinacional, por exemplo, tem interesse em saber como julgam os tribunais para poderem produzir e distribuir seus produtos.

${ }^{3}$ Despiciendo citar Marx, para quem a infraestrutura econômica influencia decisivamente a superestrutura formada pelo direito, a moral, a política, a cultura etc.

${ }^{4}$ Embora não tenha havido substituição do modo de produção capitalista por outro, é notável a revolução tecnológica ocorrida com o advento da telemática e da rede mundial de computadores que, no dizer de Castells, configurou um mundo globalizado, informatizado e em rede, por onde transitam os fluxos de dinheiro e poder.

${ }^{5}$ Para Ross, até mesmo o direito penal e o direito tributário são ramos do direito privado.
} 
Dissemos a meio do caminho, porque existem normas de competência que constituíram e estabeleceram competências, bem como limites ao poder de Tribunais Internacionais, como a Corte Interamericana de Direitos Humanos, por exemplo.

Falta-lhes, todavia, para constituírem regramento de direito público, na concepção de Ross, a possibilidade de submeter o Estado com sanções efetivas, conducentes à efetiva aplicação de suas normas pelos tribunais estatais. Note-se que os tribunais estatais não integram uma estrutura hierárquica na qual, no ápice, estejam tribunais internacionais. Logo, não há recursos a serem interpostos para as Cortes Internacionais. E ademais, no atual estágio de desenvolvimento e eficácia do direito internacional, a tradição cultural, apontada por Ross como fonte do direito, especialmente no caso de lacunas, só pode ser interpretada eficazmente por tribunais estatais.

São os magistrados das Cortes Constitucionais e quejandas que terão a consciência da necessidade social de aplicação de normas de direito internacional, conforme essa atmosfera da tradição cultural. Só assim as normas de direito internacional encontrarão terreno propício para se desenvolverem com a máxima eficácia. Daí a importância de o Direito Internacional ser constitucionalizado.

Por mais que soberania tenha sido mitigada, é fato que o monopólio da força continua nas mãos do Estado. Esse fato parece irretorquível para afirmar que o monismo é um modelo que não explica o fenômeno jurídico (direito em ação). E o dualismo também parece ultrapassado, na medida em que o direito internacional carece desse monopólio da força, único a conferir coerência e significado à ordem jurídica.

Assim, o diálogo entre o direito internacional e o direito estatal, no atual estágio de desenvolvimento do primeiro, só tem viabilidade com a sua constitucionalização. Portanto, com base na Escola do Realismo Jurídico de Alf Ross, não há se falar em um modelo ideal para a conferência de maior eficácia ao direito internacional, mas em um modelo que explique a realidade do direito como um todo de coerência e significação. E tal modelo, parece-nos, só pode ser o da constitucionalização do direito internacional.

\section{REFERÊNCIAS BIBLIOGRÁFICAS}

ALEXY, R. Conceito de validade do direito. SP: WMF Martins Fontes Ltda., 2011.

DEL VECCHIO, G. Filosofía Del Derecho. 6.ed. Barcelona: Bosh, 1953.

HART, H. O conceito de direito. 6.ed. Lisboa: Fundação Calouste Gulbenkian, 2011.

KELSEN, H. Teoria Pura do Direito. 5.ed. Coimbra: Armênio Amado Editor, 1979.

MAZZUOLI, V. Tratados Internacionais de direitos humanos e direito interno. São Paulo: Saraiva, 2010.

MAYAER, Max Ernest. Filosofía Del Derecho. 2.ed. Madrid: Editorial Labor S.A., 1937.

MONTORO, André Franco. Introdução à Ciência do Direito. 9.ed. Volume I. São Paulo: Editora Revista dos Tribunais, 1980.

ROSS, Alf. Direito e Justiça. 2.ed. São Paulo: Edipro, 2007.

STRAUSS, Leo. Direito Natural e História. São Paulo: Editora WMF Martins Fontes Ltda., 2014. 